\title{
Use of Oral Misoprostol for the Treatment of Incomplete Abortion
}

\author{
Kayastha S, ${ }^{1}$ Tuladhar $\mathbf{H},{ }^{2}$ Gurung $S,{ }^{1}$ Jaishe $\mathbf{S}^{1}$ \\ ${ }^{1}$ Department of Obstetrics and Gynaecology, Nepal Medical College Teaching Hospital \\ ${ }^{2}$ Department of Obstetrics and Gynaecology, KIST Medical College Teaching Hospital, Nepal.
} Aims: This study was done to assess the feasibility and acceptability of use of Misoprostol 600 mcg orally for treatment
of incomplete abortion.

Methods: A hospital based prospective study was carried out in the Department of Obstetrics and Gynaecology of Nepal Medical College Teaching Hospital from $1^{\text {st }}$ November 2010 to $30^{\text {th }}$ May 2013. All cases of first trimester incomplete abortion diagnosed clinically or by ultrasonogram were included in the study. They were given $600 \mathrm{mcg}$ of Misoprostol orally. They were sent home, with advice to come for follow up after one week. Routine Ultrasound was carried out on follow up visit to confirm complete abortion. The side effects, complications and patient satisfaction was assessed and recorded.

Results: Out of 86 patients, $8.1 \%$ (7) had to undergo surgical evacuation. So the success rate was $91.9 \%$ (79 cases). All the cases which needed evacuation were of higher gestation, that is, nine weeks or more. The commonest side effect was severe abdominal pain (81.4\%). Three cases required emergency surgical evacuation within 24 hours due heavy bleeding.

Conclusions: It is feasible and acceptable to use Misoprostol orally for medical evacuation, especially in earlier gestation of first trimester incomplete abortion. Side effects were common but were acceptable and tolerable by the patients.

Keywords: incomplete abortion, misoprostol, side effects, success.

\section{INTRODUCTION}

Manual vacuum aspiration (MVA) is the effective treatment of incomplete abortion. But it requires specialized equipment and skill and risks of complications like cervical trauma, uterine perforation, infections etc. Some studies have shown that expectant management is effective in most of the cases of incomplete abortion. ${ }^{1,2}$ But it is not feasible for those patients who stay far away from health facilities. Expectant management is also associated with infection (3\%) and required emergency evacuation in $7 \%$ of the cases. ${ }^{3}$ Many studies ${ }^{4-6}$ have indicated that the uterotonic properties of the $\mathrm{PGE}_{1}$ (Misoprostol) make it a safe and highly effective method of evacuating the uterus in cases of incomplete abortion. Some studies were conducted with multiple, oral doses of Misoprostol. ${ }^{7,8}$ There were also studies where Misoprostol was used vaginally for treating incomplete abortion with similar success rate, ${ }^{9,10}$ but women may feel vaginal route less acceptable than oral route and the chance of introduction of infection may increase. Hence this study was conducted to assess the feasibility, acceptability and success of using oral Misoprostol $600 \mathrm{mcg}$ in medical evacuation for incomplete abortion of first trimester.

\section{CORRESPONDENCE}

Dr Sanita Kayastha

Department of Obstetrics and Gynecology,

Nepal Medical College Teaching Hospital, Kathmandu, Nepal.

Email: sanita_kayastha@hotmail.com

Phone: +977-98510891893

The papers in this journal are published under the terms of the Creative Commons Attribution License. Users are allowed to read, download, copy, distribute, print, search, or link to the full texts of the articles in this journal without asking prior permission from the publisher or the author. 


\section{METHODS}

It was a hospital-based study carried out from 1st November 2010 to 30th May 2013 in Nepal Medical College Teaching Hospital. All cases of incomplete abortion diagnosed clinically or by ultrasound were included. Those patients who had incomplete abortion ofgestation weeks 12 or less with stable vital signs, without anaemia and history of Misoprostol allergy were included in the study. Informed written consent was taken. Then patient was given tablet Misoprostol $600 \mathrm{mcg}$ orally. They were observed for three hours for side effects, per vaginal bleeding and expulsion of product of conception. Then they were sent home with advice for follow up after one week. They were given prophylactic antibiotics. Painkiller was prescribed as per need for pain management. Routine ultrasound was carried out during follow up visit for confirmation of complete evacuation. If evacuation was complete, the patient was released from the study but if not then the woman was offered the choice between additional follow up visit in one week or immediate surgical evacuation. During follow up, the amount of blood loss, side effects of the drug, whether tolerable or not and level of satisfaction were inquired. All the data were recorded and statistical analysis was done.

\section{RESULTS}

There were total 86 patients enrolled in the study during the period of two and half years. Out of which $56(65.1 \%)$ were of spontaneous abortion and 30 (34.9\%) were of induced abortion. The age ranged from 18 to 35 years. The gestational age ranged from 5 to 12 weeks (Table 1 ).

Table 1. Relation of gestation age and medical evacuation $(n=86)$.

\begin{tabular}{ll}
\hline Gestational age & $\begin{array}{l}\text { Failure of complete } \\
\text { evacuation }\end{array}$ \\
\hline 7 to 8 weeks & $1(1.2 \%)$ \\
9 to 12 weeks & $6(6.98 \%)$ \\
\hline
\end{tabular}

Among the 86 patients, only 7(8.1\%) had to undergo surgical evacuation. So the success rate was $91.9 \%$ (79). Among the failed cases, all were of 9 weeks or more gestation (Table 1). Regarding side effects of the medication, almost half of the patient had nausea 48 (55.8\%), 70 (81.4\%) patients had pain in abdomen, 11 (12.8\%) had diarrhea, 13 (15.1\%) had fever with chills and rigor (Table 2).

Table 2. Side effects of Misoprostol $(n=86)$.

\begin{tabular}{ll}
\hline Side effects & Number (\%) \\
\hline Nausea & $48(55.81 \%)$ \\
Vomiting & $12(13.95 \%)$ \\
Abdominal pain & $70(81.40 \%)$ \\
Diarrhoea & $11(12.79 \%)$ \\
Fever with chills & $13(15.12 \%)$ \\
\hline
\end{tabular}

Heavy bleeding occurred in $10(11.6 \%)$ patients (Table 3). Three patients required emergency surgical evacuation within 24 hours due to heavy bleeding. One $(1.1 \%)$ case had prolonged and excessive bleeding which lasted for two weeks. There were two cases of prolonged lower abdominal pain, one case of pelvic inflammatory disease and one case of anaemia. Over all, the satisfaction level of the patients was high as $71(82.6 \%)$ patients were satisfied with the method, $9(10.5 \%)$ patients were very satisfied and only $6(6.9 \%)$ patients were unsatisfied (Table 4 ).

Table 3. Complications of medical evacuation $(\mathrm{n}=86)$.

\begin{tabular}{ll}
\hline Complications & Number (\%) \\
\hline Heavy bleeding & $10(11.63 \%)$ \\
Prolonged bleeding & $8(9.30 \%)$ \\
Prolonged abdominal pain & $1(1.16 \%)$ \\
Infection & $1(1.16 \%)$ \\
Anaemia & $1(1.16 \%)$ \\
\hline
\end{tabular}

\section{DISCUSSION}

The use of Misoprostol for medical evacuation is an effective method as shown by this study, with a high success rate of $91.9 \%$ (Table 1). The success rate seems to be a bit lower as compared to other studies which used the same regime of Misoprosto ${ }^{11,12}$ where it was $99 \%$ and $94.5 \%$. The higher failure rate in our study may be due to use of routine ultrasound in the 
first week in all cases to confirm complete evacuation.

The success was more in earlier gestation. In another study similar results were reported with the success rate of $100 \%$ in 6 weeks or less, $86.3 \%$ in 7 to 9 weeks and $87 \%$ in 10 to 12 weeks. ${ }^{13}$ Tang et al ${ }^{14}$ reported the commonest side effect of Misoprostol to be diarrhea. In our study, although the side effects were common; they were reported to be tolerable and acceptable by the patients (Table 2). The commonest was pain in abdomen $70(81.4 \%)$. The simplicity of use, fast action, non-invasiveness and cost effectiveness of the medical evacuation outweighed the side effects. There was only one case of infection. The less number of infections may be due to use of routine antibiotics for all patients and exclusion of already infected cases. Shannon et $\mathrm{a}^{15}$ reported that the rate of infection was only $0.9 \%$ and none in the study done by Gurung et al. ${ }^{13}$ One case of anaemia with prolonged bleeding came to hospital only on the $17^{\text {th }}$ day with heavy bleeding and required three pints of blood transfusion and there were three cases of surgical evacuation done within 24 hours due to excessive bleeding (Table 3). So the medical evacuation should be used in selected cases whostay close to health facility with proper set up, where emergency surgical evacuation can be done specially for those cases with higher gestation. As regarding patient satisfaction $82.6 \%$ were satisfied (Table 4). Patient satisfaction rate was higher than in the study done by Gurung et al (64.2\%) and lower than the study done by Sajuna et al (88\%) ${ }^{16}$ and $86.6 \%$ in Ninimak et al. ${ }^{17}$

In a poor country like ours where surgical evacuation facilities are limited due to lack of skilled surgical providers and equipment, the use of just three tablets of Misoprostol orally given by health providers can be life saving and help us in reducing the maternal mortality. But larger studies need to be carried out in rural set-ups, especially where ultrasound facility is not available to see the feasibility of medical evacuation. Although Misoprostol is a very effective drug, thorough knowledge of the dosage, side effects, complications and contraindications should be given to health personnels who prescribe it.

\section{CONCLUSIONS}

Misoprostol $600 \mathrm{mcg}$ given orally has been shown to be an acceptable, effective and safe method of medical management in early gestation incomplete abortion. Use in higher gestation increases risk of bleeding and need for surgical evacuation. Misoprostol 600 mcg was associated with minor side effects that were tolerable by the patients.

\section{REFERENCES}

1. Chipchase J, James D. Randomised trial of expectant versus surgical management of spontaeneous miscarriage. $\mathrm{Br} \mathrm{J}$ Obstet Gynaecol. 1997;104:840-1.

2. Neilsen S, Hahlin M. Expectant management of firsttrimester spontaeneous abortion. Lancet. 1995;345:84-6.

3. Ancum WM, Van der Veen F. Management of first trimester spontaneous abortion. Lancet. 1995;345:1179-80.

4. Trinder J, Brocklehurst P, Porter R, Read M,Vyas S, Smith L. Management of miscarriage: expectant, medical or surgical? Results of randomized controlled trial miscarriage treatment (MIST) trial\}. Br J Obstet Gynecol. 2006;332:1235-8.

5. Moodliar S, Bagrattee JS, Moodly J. Medical vs surgical evacuation of first trimester spontaeneus abortion. Int $J$ Gynaecol Obstet. 2005;353:761-9.

6. Ngoc NTN, Blum J, Durocher J, Quan TTV, Winkoff B. Medical Management of incomplete abortion using 600 versus $1200 \mathrm{mcg}$ of misoprostol. Contraception. $2005 ; 72: 438-42$

7. Pandian Z, Asok P, Templeton A. The treatment of miscarriage with oral misoprstol. Br J Obstet Gynaecol. $2001 ; 108: 213-4$

8. Pang MW, Lee TS, Chung TK. Incomplete miscarriage: a randomized controlled trial comparing orally with vaginal misoprostol for medical evacuation. Hum Reprod. $2001 ; 16: 2283-7$

9. Ngai SW, Chn YM, Tang OS, Ho PC. Vaginal misoprostol as medical treatment for first trimester spontaneous miscarriage. Hum Reprod. 2001;16:1493-6.

10. Sahin HG, Sahin HA, Kocer M. Randomised outpatient clinical trial of medical evacuation and surgical curettage in incomplete miscarriage. Eur J Contrcpt Reprod Health Care. $2001 ; 6: 141-4$ 
11. Shwekerela B, Kalumuna R, Kipingili R, Mashaka N, Westhimer E, Clark W, et al. Misoprostol for treatment of incomplete abortion at the regional hospital level: results from Tanzania. Br J Obstet Gynaecol. 2007;114:1363-7.

12. Doa B, Blum J, Thieba B, Raghavan S, Quedraego M, Lankoande J, et al. Is misoprostol a safe, effective and acceptable alternative to manual vacuum aspiration for postabortion care? Results from a randomized trial in Burkina Faso, West Africa. Br J Obstet Gynaecol. 2007;114:1368-75.

13. Gurung G, Rana A, Baral J. Use of Misoprostol in the management of early pregnancy loss. Nepal J Obstet Gynaecol. 2012;7:9-13.
14. Tang OS, Germzeill-Danielsson K, Ho PC. Misoprostol: pharmakinetic profile, effects on the uterus and side effects. Int J Gynaecol Obstet. 2007;99:5160-7.

15. Shannon C, Brothers LP, Phillip NM, Winikoff B. Infection after medical abortion: a review of the literature. Contraceptive. 2004;70(3):183-90.

16. Saguna RK, Vidya AT, Shafi AS. Vaginal misoprostol in early pregnancy failure. Al Ameen J Med Sci. 2010;3(3):195-200.

17. Ninimaki M, Jouppila P, Martikainen H, Talvensaari-Matilla A. A randomized study comparing efficacy and patient satisfaction in medical or surgical treatment of miscarriage. Fertil Steril. 2006;86(2):367-72. 